\title{
O USO DA GAMIFICAÇÃO PARA FORTALECIMENTO DAS COMPETÊNCIAS DE UM LÍDER
}

\author{
BRASÍLIA/DF MAIO/2018 \\ Erdman Correia da Silva - Sabin - erdman.silva@sabin.com.br \\ Aline Christianne Silva Vargas - Sabin - aline.vargas@sabin.com.br \\ Tipo: Relato de Experiência Inovadora (EI) \\ Categoria: Conteúdos e Habilidades \\ Setor Educacional: EDUCAÇÃO CORPORATIVA
}

\begin{abstract}
RESUMO
Através do desenvolvimento interno de um jogo de tabuleiro, ambientado no período medieval das batalhas do Rei Arthur, os participantes são convidados a explorar uma terra desconhecida, discutir temas relacionados à liderança de uma forma geral, mas também alinhada as 8 competências do Líder Sabin, seus propósitos e suas importâncias.

O jogo funciona de forma cooperativa, mas inicialmente isso não é explicitado para os participantes, que devem ceder a necessidade de competição no decorrer do jogo, para que o mesmo flua, levando em consideração que o objetivo final do jogo é o mesmo para todos os participantes.

Os grupos são divididos em 5 trios, cada um representado por um herói característico das histórias do Rei Arthur e devem usar de estratégias e trabalho em equipe desde o princípio para encontrar 7 pergaminhos escondidos no tabuleiro. Estes por sua vez possuem a descrição das 7 competências do líder Sabin, que quando conquistadas revelará "O Segredo do Graal", que nada mais é que a oitava competência base adotada para todo e qualquer líder: a Paixão por servir.

No decorrer da jornada, eles encontrarão itens e informantes que os auxiliarão na conquista do objetivo, enfrentarão inimigos para a conquista desses pergaminhos e também dificuldades propostas pelos vilões do jogo.

Dentro da história, a Feiticeira Morgana e seu aliado Mordred, tomam posse do Reino, matando o Rei Arthur e seus aliados, porém, através de uma última magia poderosa, Merlin traz para os tempos medievais os herdeiros do reino, que são os participantes do jogo. Eles carregam a responsabilidade de honrar seus ancestrais, Rei Arthur, Percival, Merlin, Lancelot e Guinevere, em busca do Segredo do Graal, que só será revelado, com a união dos sete pergaminhos escondidos.
\end{abstract}

Palavras-chave: gamificação, liderança, engajamento, competências, planejamento estratégico, propósito, desenvolver pessoas, visão de negócio, estratégia, promover e facilitar mudanças, paixão por servir, equipes de alto desempenho, inovação, jogo de tabuleiro, jogo educacional, jogo para liderança

AGRADECIMENTOS

SABIN MEDICINA DIAGNÓSTICA

TODA A EQUIPE CORPORATIVA, COORDENAÇÃO, GERENCIA E DIRETORIA. PLAYTESTERS ENVOLVIDOS NO DESENVOLVIMENTO DO JOGO. 


\section{1 - INTRODUÇÃO}

Após o mapeamento das competências da liderança dentro da organização, foi demandando para a equipe da Universidade Corporativa a criação de uma Trilha para os Líderes, que permeasse conhecimentos pertinentes a essas competências.

Para compor essa trilha foram adotadas ações educacionais tanto na modalidade presencial quanto virtual e uma dessas ações planejadas seria uma ação gamificada, com objetivo de trabalhar as competências de forma lúdica e reflexiva com os participantes e representando também o lançamento da trilha.

\section{2 - OBJETIVOS}

Desenvolver líderes engajados, alinhados as competências organizacionais, que tenham paixão por servir e visão de negócio. Que liderem através dos valores e propósitos da organização e estejam aptos a desenvolver pessoas. E por fim, compor equipes de alto desempenho, que utilizem da inovação em seu dia a dia, que saibam planejar estrategicamente suas ações facilitando a gestão de mudanças necessária em toda a organização.

\section{3 - REFERENCIAL TEÓRICO}

O termo gamification (ou em português, gamificação), nada mais é que o uso de técnicas e mecânicas existentes em jogos para aplicações fora do contexto de jogos propriamente dito. Usar de jogos nas empresas vai muito além de colocar os colaboradores para "brincar". Os elementos como competição ou cooperação, resolução de problemas, fases, premiações, desafios e entre outros, existem para trabalhar vários aspectos que podem ser dificuldades comuns entre os profissionais ou alavancar alguma temática que seja necessária dentro da organização.

A gamificação pode ser definida de forma mais consistente como sendo uma estratégia apoiada na aplicação de elementos de jogos para atividades corporativas ou educacionais em que é utilizada para influenciar e causar mudanças no comportamento de indivíduos e grupos. Para Sebastian Deterding a gamification é um fenômeno da Tecnologia da Informação cujo conceito é considerado por alguns apenas um modismo e, por outros, uma solução real para diversos problemas organizacionais.

Apesar do termo ter sido criado na década de 70 por Nick Pelling, foi somente em meados de 2010 que ele começou a ganhar popularidade, quando a Game Designer 
Jane McGonigal fez uma palestra no TED Talk, falando sobre como jogos podem fazer um mundo melhor.

Segundo o livro Gamification, Inc., existe um abismo enorme entre o processo dos games e do trabalho tradicional. Enquanto no jogo, as tarefas são planejadas para serem executadas de forma divertida e com um objetivo bem definido, tendo o personagem assumido um feedback constante sua evolução pessoal clara e tangível, no trabalho, as tarefas são vistas como repetitivas e maçantes e o feedback, muitas vezes, é inexistente. Com isso, a evolução pessoal não é percebida pelo colaborador. Esse processo rígido acaba afetando o desempenho dos funcionários e os resultados finais da empresa. É aí que a gamificação entra em ação. Podendo contribuir para a mudança de cenário, tornando o ato de trabalhar agradável, divertido e motivador.

Baseando-se nesses conceitos e em atividades e cursos realizados presencialmente, foi decidido pela empresa que a criação e desenvolvimento de um jogo corporativo para trabalhar as competências da liderança era necessário e que as mecânicas lúdicas de uma ação gamificada dariam celeridade no alcance das metas organizacionais.

\section{4 - PROCEDIMENTOS METODOLÓGICOS}

O jogo para a liderança, intitulado "Virtudes de Camelot", foi desenvolvido internamente, com o propósito de gerar aprendizado, interação entre os participantes, maior entendimento das competências do líder e também reflexões acerca do seu papel individual dentro da organização e de sua própria equipe. Tudo isso utilizando elementos múltiplos da gamificação, com entretimento, ludicidade e trabalho em equipe.

Tendo como base as 8 competências do Líder Sabin, o processo de criação seguiu 4 etapas para o desenvolvimento: Definição do Tema, brainstorm, Criação do Protótipo e Playtest.

$\mathrm{Na}$ definição do tema a ser trabalhado decidimos utilizar o universo dos Cavaleiros da Távola Redonda, pela existência do Rei Arthur como uma figura de líder conhecido. Utilizamos elementos característicos dos storytellings de RPGs de mesa, como a criação de uma história original, partindo de um universo já existente, uso de itens que tragam uma identificação com a história como a Espada Excalibur e o Cajado do mago Merlin, vilões comumente conhecidos como a Feiticeira Morgana, entre outros.

A partir daí, tivemos uma seção de brainstorm com os integrantes envolvidos na criação do jogo para levantamento de pontos que poderiam existir dentro do jogo e outros que 
seriam indispensáveis para a experiência gamificada, como por exemplo, a relação da história com as competências a serem trabalhadas, como seriam os momentos de discussões entre os participantes do jogo, para reflexão dos temas a serem trabalhados, entre outros.

Depois disso, um protótipo foi desenvolvido, trabalhando dois tabuleiros, um principal que é composto pelo mapa no qual os personagens se movimentam e um auxiliar, utilizado para que as cartas que foram criadas fiquem organizadas.

Por último, foram realizadas seções de Playtests, momento onde o jogo é aplicado de maneira completa, para que as mecânicas e regras definidas inicialmente fossem testadas e para que fosse possível avaliar se os objetivos estipulados inicialmente poderiam ser alcançados. As turmas criadas para os playtests não envolviam colaboradores da liderança, pois esse momento existe para avaliação e validação e não era de interesse no momento, estragar a experiência que seria proporcionada aos líderes com o jogo na versão final. Todos os feedbacks de melhoria foram levados em consideração e ao total foram realizadas 5 turmas de playtest para que o jogo chegasse na sua forma final.

\section{5 - APRESENTAÇÃO E DISCUSSÃO DOS RESULTADOS}

A aplicação de uma seção ideal do jogo parte da necessidade de presença de 15 participantes que são divididos em 5 trios. Cada trio é representado por um herói do universo de Camelot. Esses heróis são o Rei Arthur, Lancelot, Merlin, Guinevere e Percival.

Cada trio possui 5 pontos de ação por turno que devem ser distribuídos entre movimentação e pesquisa. Cada ponto de movimentação no tabuleiro custa 1 ponto de ação e as cartas de pesquisa possuem 3 valores: 1 ponto, 2 pontos ou 3 pontos de ação. Eles devem pensar estrategicamente como distribuir esses pontos a cada rodada. Ao iniciar um novo turno, o trio tem novamente 5 pontos de ação. Os pontos que ocasionalmente sobrem de uma rodada para outra não são acumulados.

As cartas encontradas no decorrer da jornada são dividias em:

- Dicas: Cartas que trazem informações importantes sobre a localização de itens que auxiliarão na conquista do objetivo;

- Desafios de Merlin: Aqui os participantes devem discutir temas voltados para as 
competências da liderança, em troca de pontos de ações extras que devem ser utilizados imediatamente;

- Contextualização Histórica: 15 cartas que contam o enredo completo do jogo e que também servem de auxílio na conquista do objetivo;

- Cartas de Clima: Divididas entre Nublado, Sol Quente, Tempestade, Chuva e Nevasca, as cartas de clima interferem negativa ou positivamente na movimentação dos personagens pelo tabuleiro;

- Feitiços de Morgana: Cartas que tem como função, atrapalhar o planejamento e o desenvolvimento dos participantes no decorrer da jornada;

- Itens: Servem para auxiliar os jogadores a concluírem missões e derrotar inimigos;

- Vilões: O jogo possui quatro vilões, onde cada um guarda um pergaminho sobre seu domínio. Os vilões são a Feiticeira Morgana, Mordred e Seu Dragão, as Ninfas das Hespérides e o Leviatã de Gelo. Cada um só pode ser derrotado após uma arma específica ser encontrada;

- Templos: Cada templo possui um item de uso único que pode ser usado a qualquer momento do jogo.

- Informantes: Relatam a localização de perigosas masmorras que existem pelo mapa.

- Masmorras de Mordred: Cartas que aprisionam os jogadores por tempo determinado.

O objetivo do jogo é que os participantes encontrem 7 pergaminhos que estão escondidos no mapa, para que com esses 7 pergaminhos, eles liberem "O Segredo do Graal". Cada pergaminho traz uma descrição de uma das 7 competências do líder Sabin. Ao final do Jogo, eles precisam atribuir a descrição da competência que está na carta, com qual competência eles acham que a carta está se referindo. Ao acertarem, eles abrem o oitavo pergaminho que traz a definição da oitava competência do líder Sabin, que é a "paixão por servir".

A mecânica do jogo permite que os participantes inicialmente criem uma competição entre os grupos, mas no decorrer da jornada eles sempre entendem que precisam um do outro para conseguir conquistarem o objetivo e que a única forma de vencer o jogo é trabalhando em equipe. 
Tivemos resultados surpreendentes após a aplicação do jogo nas turmas participantes. Tivemos até o presente momento, cinco turmas que auxiliaram no desenvolvimento do modelo final do jogo, assim como, nas correções necessárias. O engajamento e a compreensão das competências da liderança, que dentro do Sabin é conhecido como "Humanizar - O jeito Sabin de Liderar" aumentou em larga proporção.

Outro resultado surpreendente foi a decisão da equipe de Recursos Humanos em utilizar a aplicação do jogo nos processos seletivos para escolha de novos líderes. Pelo fato do jogo trabalhar todos os elementos previamente citados, ficou evidente que sua aplicação para potenciais líderes auxiliaria a equipe de talentos humanos a selecionar novos líderes, através do seu desempenho e relação interpessoal no decorrer do jogo. As discussões levantadas durante os Desafios de Merlin, servem como um medidor de conhecimento da cultura da empresa, gerador de insights para novos líderes, assim como permite o posicionamento do líder em situações de conflito e em situações de dilemas éticos e morais, como ele enxerga o seu papel a partir do ponto de vista de conhecimento de mundo e também como pensa ser uma postura ideal de um líder que engaja e desenvolve pessoas.

Abaixo as imagens ilustrativas do jogo:

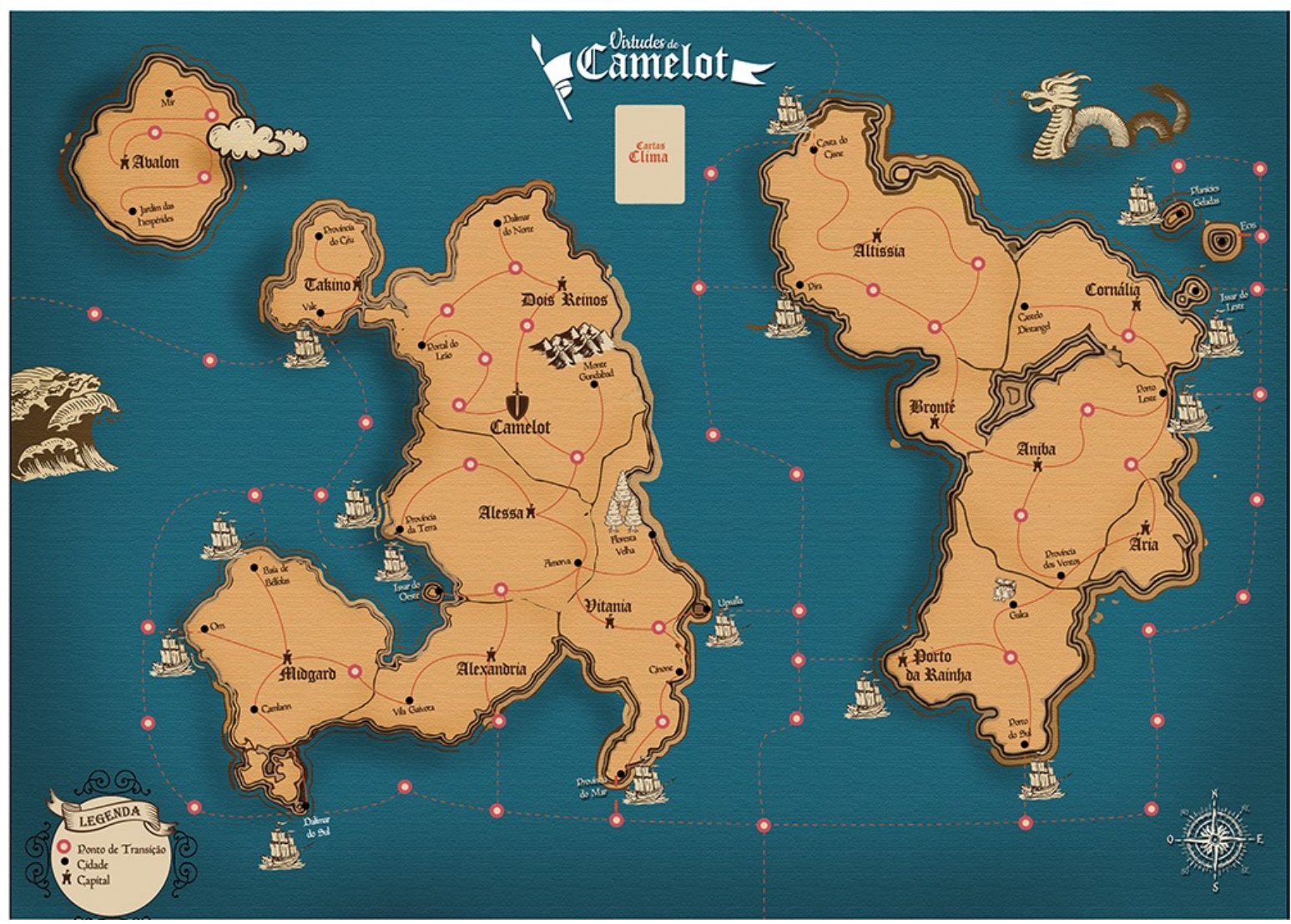



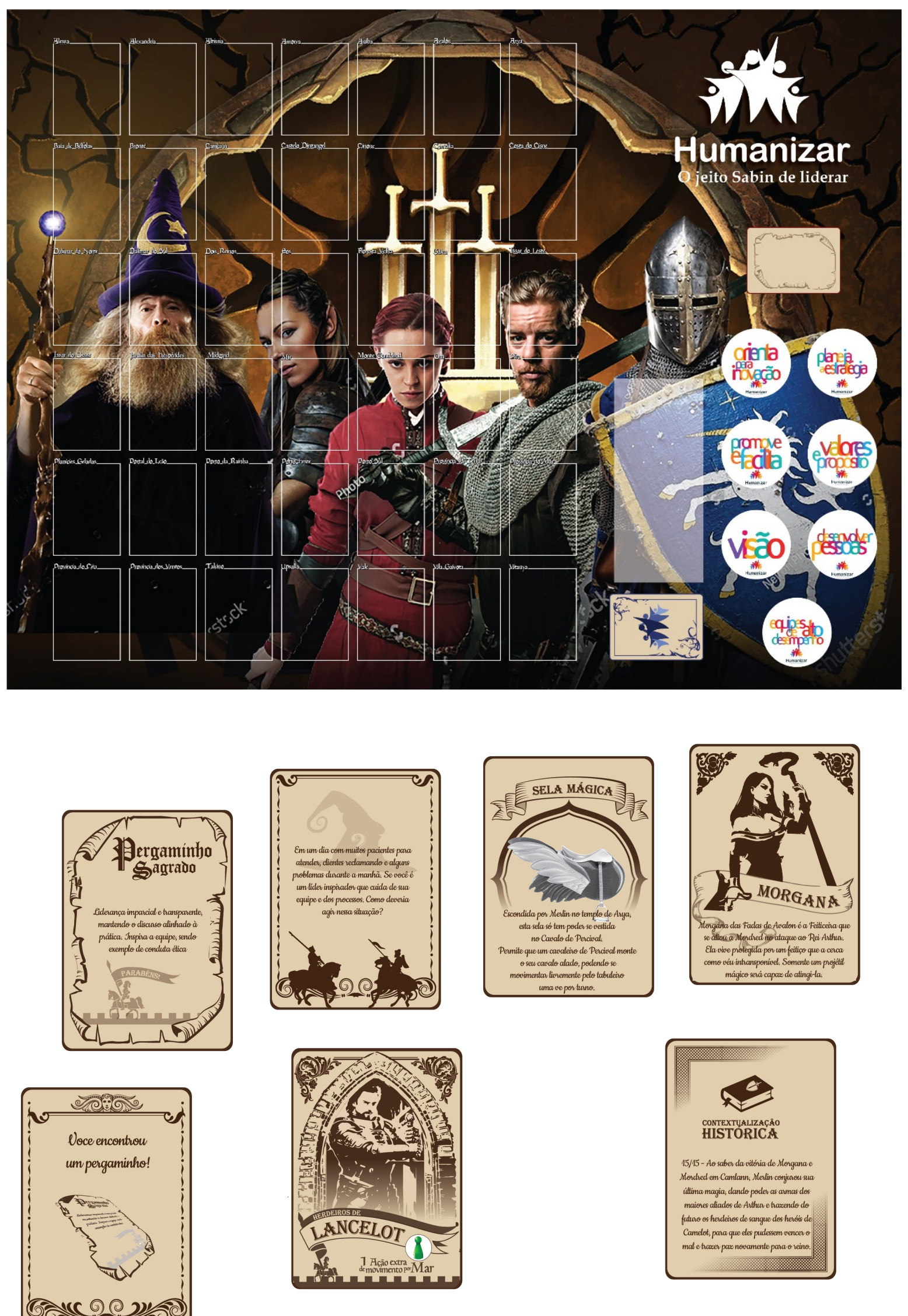

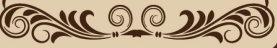




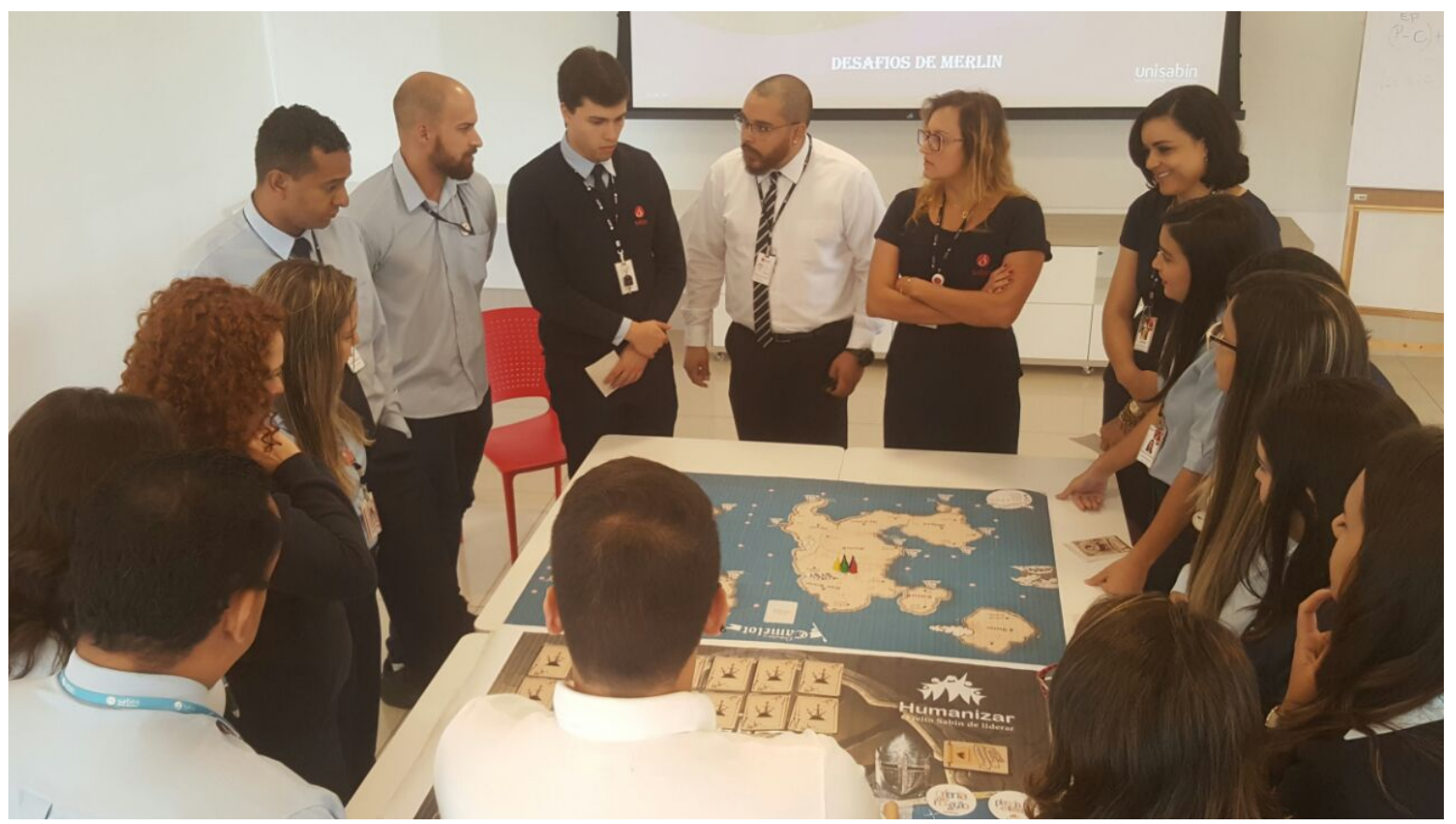

6 - CONSIDERAÇÕES FINAIS

O jogo atualmente é aplicado nacionalmente em todas equipes de liderança da empresa, tem tido excelente aceitação e muitos retornos positivos, principalmente sobre como o uso de uma metodologia lúdica e divertida consegue transformar um assunto denso e sério em algo leve e de fácil compreensão.

O uso da Gamificação já é algo praticado pela Universidade Corporativa da empresa, que também possui um jogo de tabuleiro que é utilizado na integração do novo colaborador para trabalhar a temática da ideologia da empresa. Dessa forma, os treinamentos gamificados para a liderança apenas reforçam as práticas inovadoras, modernas e com o intuito de firmar a cada dia, as mais variadas práticas educacionais discutidas e aplicadas no meio de educação corporativa.

\section{7 - REFERÊNCIAS BIBLIOGRÁFICAS}

BURKE, Bryan. Gamificar - Como a Gamificação motiva as pessoas a fazerem coisas extraordinárias. DVS Editora, 2015. 195p.

ALVES, Flora. Gamification - Como criar experiências de aprendizagem engajadoras. Um guia completo: Do Conceito à Prática. DVS Editora, 2015. 200p.

MATTAR, João. Metodologias Ativas para Educação presencial, Blended e a Distância. Artesanato Educacional, 2017. 118p.

VIANNA, Ysmar et al. Gamification INC. MJV Press, 2013. 139p.

MCGONIGAL, Jane. A realidade em jogo - Por que os games nos tornam melhores e como eles podem mudar o mundo. Best Seller, 2012. 378p.

PINHEIRO, Andressa; ZAGGIA, João Luiz. Gamification Humanizado - Aprenda na 
prática 12 passos para transformar suas palestras, treinamentos e reuniões em uma experiência inovadora inspirada nos jogos. Triunica Gamification Desenvolvimento Humano Criativo, 2017. 